\title{
Problems and Hopes of Neurophenomenology and First-Person Neuroscience
}

\author{
Lenka Jedličková, Michal Müller ${ }^{1}$ \\ Palacký University Olomouc
}

\begin{abstract}
Neuroscience is a dynamically developing discipline which currently influences the emergence of new research programs that combine high-tech neuroscience methodology with social science approaches. This article focuses on neurophenomenology and fields of first-person neuroscience that attempt to bridge the gap between first-person and third-person perspectives of research. The aim of this article is to show what areas of interest and what methodological approaches the current neurophenomenology and first-person neuroscience is taking, especially in the context of a summary of the basic problems associated with this research program. Efforts to link neuroscience to other disciplines, that traditionally deal with the phenomena of different levels of analysis, are associated with several conceptual and methodological problems. Although no definitive solution to these problems is in sight, neurophenomenology provides a number of stimuli for new reflections on the nature of mental states and brings new perspectives for research within social neuroscience.
\end{abstract}

\section{Keywords}

First-Person Methodology; First-Person Neuroscience; Neurophenomenology; Philosophy of Neuroscience

\section{Contact Address}

Mgr. et Bc. Lenka Jedličková, Department of Philosophy, Palacký University Olomouc, Kř́žǩvovkého 12, 77180 Olomouc, Czech Republic; e-mail: lenka.jedlickova04@upol.cz

Mgr. Michal Müller, Ph.D., Department of Applied Economics, Palacký University Olomouc, Křížkovského 12, 77180 Olomouc, Czech Republic; e-mail: michal.muller02@upol.cz

${ }^{1}$ This paper was supported by the project Reflection of Current Actualisations of Selected Approaches in Continental Philosophy (IGA_FF_2019_008) of Palacký University Olomouc. 


\section{Introduction}

We have been experiencing the dynamic development of neuroscience over the last few decades. At present, the scope of neuroscience disciplines is being expanded and new research programs in the field of social neuroscience are especially being developed. These tendencies to link neuroscience to other disciplines, that traditionally deal with the phenomena of different levels of analysis, are associated with methodological, theoretical and philosophical issues. ${ }^{2}$ The complex nature of these problems leads to new interdisciplinary investigations and one can talk about philosophy of neuroscience or neurophilosophy within philosophy. ${ }^{3}$ These fields of applied philosophy deal with these issues and have become an influential part of cognitive science.

In this article we focus on neurophenomenology. The neurophenomenological approach is based on an effort to combine two streams of mind exploration - the prospect of modern neuroscience, based on objective quantitative methods, in this respect the study of brain activity in the context of ongoing mental events, and a perspective based on traditional contemplative, introspective ways of mind exploration, that have their origins in ancient philosophical concepts. Neurophenomenology, which has been associated with the work of Francisco Varela, has attempted to overcome since its inception the level of naive introspection by the role of a well-trained experimental subject. ${ }^{4}$

There is therefore no doubt that the effort to use first-person data is associated with extremely complicated philosophical problems. One of these problems is the issue of reductionism. Advocates of the neurophenomenological research have to find a way to demonstrate the irreducibility of unique experience and first-person processes or at least their usefulness. Other serious questions then relate to whether neurophenomenology is able to come up with knowledge that cannot be captured through proven scientific methods. ${ }^{5}$ In addition to these difficulties, however, neurophenomenology provides hope and new light on the exploration of mental states and consciousness. The aim of this paper is to demonstrate what areas of interest and what methodological approaches the current neurophenomenology or so-called first-person neuroscience is taking, especially in the context of a summary of the basic problems associated with this research program.

\footnotetext{
2 The ambitious research program of neuroeconomics, which attempts to link neuroscience, psychology and economics in a unified discipline, represents an example of various problems. See Michal Müller, "Challenges and Problems of Neuroeconomics: Several Tasks for Social Scientists," Teorie védy / Theory of Science 40, no. 2 (2018): 157-190.

${ }^{3}$ John Bickle, Peter Mandik and Anthony Landreth, "The Philosophy of Neuroscience," in The Stanford Encyclopedia of Philosophy ed. Edward N. Zalta (Summer 2012 Edition), https://plato.stanford.edu/archives/ sum2012/entries/neuroscience.

${ }^{4}$ Gaëlle Desbordes and Lobsang T. Negi (2013). "A New Era for Mind Studies: Training Investigators in Both Scientific and Contemplative Methods of Inquiry," Frontiers of Human Neuroscience 7 (November 2013): 1. ${ }^{5}$ Patricia Bockelman, Lauren Reinerman-Jones and Shaun Gallagher (2013). "Methodological Lessons in Neurophenomenology: Review of a Baseline Study and Recommendations for Research Approaches," Frontiers in Human Neuroscience 7 (October 2013): 3.
} 
The first part of the article briefly outlines the phenomenological roots of the research program. The second part characterizes the basic perspectives of neuroscience research and demonstrates how the mental states are viewed within these perspectives. The third part describes several selected areas where the neurophenomenological method is used and indicates how the first-person data contribute to these fields. The fourth part deals with conceptual and methodological problems of neurophenomenology. The discussion consequently summarizes the previous debate.

\section{The phenomenological background}

The most important concept in Husserl's phenomenology is intentionality. This means that our consciousness is always intentional - all our psychological acts are in a relationship with the external world (consciousness is always consciousness of something): we always think, remember, believe, hate, etc., "something" in the external world (Husserl explained it as "aboutness"). Every mental phenomenon is derived from physical phenomenon, whereby we must distinguish between the act of consciousness and the phenomenon. ${ }^{6}$ The roots of neurophenomenology go back to Husserl and Merleau-Ponty's ${ }^{7}$ phenomenology and combine it with neuroscience.

Neurophenomenology is based on Husserl's basic concept, but it is important to note at the beginning of the enquiry about its relevance that there is great difficulty in another aspect of research. Among other things, it is important that the phenomenological method does not only concern the phenomenological reduction method (bracketing all assumptions about the existence of the external world and attempting to capture the eidetic invariant of the matter in consciousness), but also the issue of time as described by Husserl in his On the Phenomenology of the Consciousness of Internal Time. ${ }^{8}$ It is precisely the issue of three time dimensions (protention, impression and retention) that is crucial for the analysis of consciousness and its contents. This is pointed out in the text of Natalie Depraz and Thomas Desmidt. They claim that "there is a methodological-ontological obstacle to the practical implementation of the neurophenomenology hypothesis: it is the irreducible difference of level in the temporal scale between neuro-dynamics measured in milliseconds and the a priori philosophical categories that have no singular and specified experiential time sequenced access"?

${ }^{6}$ Edmund Husserl, Ideas Pertaining to a Pure Phenomenology and to a Phenomenological Philosophy - First Book: General Introduction to a Pure Phenomenology, trans. F. Kersten (The Hague: Nijhoff, 1982).

${ }^{7}$ Merleau-Ponty's phenomenology is key for cognitive science because of his efforts in naturalizing phenomenology. In contrast to Husserl, he also dealt with the body, which is inextricably linked to our consciousness and the world. (Maurice Merleau-Ponty, Phenomenology of Perception, Routledge Classics, Taylor \& Francis, 2002).

${ }^{8}$ Edmund Husserl, On the Phenomenology of the Consciousness of Internal Time (1893-1917), trans. J.B. Brough (Dordrecht: Kluwer 1990).

9 Natalie Depraz and Thomas Desmidt, "Cardiophenomenology: A Refinement of Neurophenomenology," Springer. Phenomenology and the Cognitive Sciences, 18, no. 3 (2019): 493-507. 
Unfortunately, it seems that the issue of temporality is not sufficiently reflected on within the neurophenomenological research program and only some texts deal with it explicitly. As Laughlin and Rock claim, "a factor that is often missed by philosophers debating phenomenology is that mature contemplation leads through a series of transpersonal experiences, resulting in irreversible changes in self-awareness and ego-identification," moreover, "these changes allow 'seeing' in new ways, ways that pre-epoché commentators cannot know from direct experience". ${ }^{10}$ To understand how human consciousness works, there is a need to understand the relationships between these three time phases, because the experience of time underlies the very structure of subjective life. Varela also points out the importance of the problem of present-time consciousness. He claims that temporality is inseparable from all experience and that the traditional phenomenological structure of time (protention, impression and retention) is incompatible with the physical idea of linear time. ${ }^{11}$

\section{Mental phenomena and first-person data in the context of neuroscientific approaches}

\section{First-person neuroscience}

First-person neuroscience is a field of neuroscience that focuses on research of mental states "by themselves", as opposed to the contents of these mental states in the context of how they are experienced in first person. ${ }^{12}$ This data is related to data of neuronal states obtained through a third-person perspective. Methods of first-person neuroscience may include, for example, introspective psychology or methods of phenomenology and neurophenomenology. ${ }^{13}$ On the one hand, first-person neuroscience can be understood in a broader meaning as a label for various approaches that attempt to use first-person data and combine it with third-person data (including neurophenomenology), while on the other hand the term first-person neuroscience may be more appropriate in cases where the experimental method does not involve a consistent phenomenological analysis or other elements of phenomenological research and instead employs self-reports with minimal inspiration in traditional phenomenological methodology. The term neurophenomenology, alternatively second-person neuroscience, is used for that approach which is associated with the philosophy of phenomenology.

${ }^{10}$ Charles D. Laughlin and Adam J. Rock, "Neurophenomenology. Enhancing the Experimental and CrossCultural Study of Brain and Experience," in The Wiley-Blackwell Handbook of Transpersonal Psychology, edited by Harris L. Friedman and Glenn Hartelius (John Wiley \& Sons, Ltd. Published 2013), 268.

${ }^{11}$ Francisco J. Varela, "Neurophenomenology: A Methodological Remedy for the Hard Problem," Journal of Consciousness Studies 3, no. 4 (1996): 342.

${ }_{12}$ Georg Northoff and Alexander Heinzel, "First-Person Neuroscience: A New Methodological Approach for Linking Mental and Neuronal States," Philosophy, Ethics, and Humanities in Medicine (2006), https:// peh-med.biomedcentral.com/track/pdf/10.1186/1747-5341-1-3.

${ }^{13}$ Ibid. 


\section{Neurophenomenology}

Neurophenomenology represents a scientific research program that tries to include the methodology of first-person research that produces data related to subjective experimental reports inspired by phenomenology into the state-of-the-art scientific third-person methodology of neuroscience. The relevance of the first-person data is discussed throughout the history of science and philosophy. While many scientific approaches point to the numerous difficulties of relying on subject evidence, other researchers are trying to enrich quantitative approaches to qualitative ways of exploration and seeking ways to link both methodologies. ${ }^{14}$ Unlike neurophilosophy, which draws more from an analytical tradition, neurophenomenology is based on phenomenological philosophy. This discipline arises as a research program with the ambition of bridging the explanatory gap (or at least making progress in this direction) between phenomenological and neuronal features of consciousness. ${ }^{15}$ Neurophenomenology is related to the work of Francisco Varela, ${ }^{16}$ who has tried to make progress in questions related to the hard problem of consciousness. ${ }^{17}$ The issue of consciousness is outlined in the following section. Varela's neurophenomenological method then deals with the problems and methodology of neurophenomenology.

\section{Second-person neuroscience}

Second-person neuroscience represents a term for study of "mental states that can be detected in second-person perspective by means of introspection or 'phenomenal judgment". ${ }^{18}$ In this context, neurophenomenology and investigation of neural correlates of consciousness can be considered the approach of second-person neuroscience. While first-person neuroscience focuses on conscious states, in second-person neuroscience "phenomenal" is associated with both conscious and unconscious states. As Northoff and Heinzel argue, however, these differences are often not taken into account and these approaches are not differentiated. ${ }^{19}$ As will be shown in the section on problems of neurophenomenology, critics of the first-person approach point out that data that are considered first-person

\footnotetext{
${ }^{14}$ See Bockelman et al., "Methodological Lessons in Neurophenomenology".

${ }^{15}$ Evan Thompson, Antoine Lutz and Diego Cosmelli, "Neurophenomenology: An Introduction for Neurophilosophers," in Cognition and the Brain: The Philosophy and Neuroscience Movement, ed. A. Brook and K. Akins (New York, NY: Cambridge University Press, 2005), 41.

${ }^{16}$ See Varela, "Neurophenomenology".

${ }^{17}$ Chalmers distinguishes between "hard" and "easy" problems of consciousness. Easy problems are investigable by traditional ways of cognitive science, although they pose considerable challenges. This involves explaining phenomena such as reporting mental states or focusing attention. Hard problems that relate to the explaining of phenomenal experience and questions, such as what it is like to be a conscious organism, are more complicated. See David John Chalmers, "Facing up to the Problem of Consciousness," Journal of Consciousness Studies 2, no. 3 (1995).

${ }^{18}$ Georg Northoff and Alexander Heinzel, "First-Person Neuroscience: A New Methodological Approach for Linking Mental and Neuronal States", Philosophy, Ethics, and Humanities in Medicine (2006): 3, https:// peh-med.biomedcentral.com/track/pdf/10.1186/1747-5341-1-3.

${ }^{19}$ Ibid.
} 
are actually second-person because first-person data cannot be directly examined. ${ }^{20}$ The term second-person neuroscience is also used in the context of neuroscientific research of social interaction. These second-person approaches are "based on the assumption that social cognition during social interaction is fundamentally different from social cognition during social observation (also referred to as a third-person perspective) and that the same distinction is likely to apply to the underlying behavioural and neural mechanisms" ${ }^{21}$ Experiments within this research program focus on participants who are engaged in real time and reciprocal social interactions where one brain or multiple brains are studied. ${ }^{22}$

\section{Third-person neuroscience}

While the first-person perspective was related to the immediate familiarity of the subject with his mental condition and lived experience, which is characterized by its private character, the perspective of the third person aims to ensure an objective description. This objective description may relate to changes in the nervous system and other facts that can be independently verified by testing. Research from a third-person perspective is typical of experimental neuroscience. ${ }^{23}$ Neuroscientific studies, based on the perspective of a third person, may implicitly or explicitly advocate different solutions to the relationship between mental and physical entities, or in the case of eliminative materialism to deny completely the mental entities. In this regard, as Lo Dico with the example of neuroeconomics (a branch of social neuroscience) demonstrates, neuroscientific studies often a priori assume a mind-brain type identity theory, which is a strong philosophical position that is not supported by sufficient empirical evidence. ${ }^{24}$ The problematic character of the search for the relationship between mental and physical entities is not only related to the mind-body problem but to the limitations of the results of correlation studies. The search for neuronal correlates itself is related to the problem of "the conceptualization, operationalization, and measurement of the object of inquiry", because social-psychological phenomena are difficult to define and there are several opposing concepts and theories, which leads to the important question, "what are neural correlates neural correlates of". 25

\footnotetext{
${ }^{20}$ See Daniel Dennett, Consciousness Explained (Little, Brown and Co, Boston, 1991), Leon Ciechanowski, "Has the Philosopher's Stone of the Interaction Between First- and Third-Person Data Finally been Found?," Constructivist Foundations, 12, no. 2 (2017).

${ }^{21}$ Elizabeth Redcay and Leonhard Schilbach, "Using Second-Person Neuroscience to Elucidate the Mechanisms of Social Interaction,” Nature Reviews Neuroscience 20 (2019): 495.

${ }^{22}$ Ibid.

${ }^{23}$ Michal Polák, Filosofie mysli (Praha; Kroměříž: Triton, Západočeská univerzita v Plzni, 2013), 29-30.

${ }^{24}$ Giuseppe Lo Dico, "Neuroeconomics, Identity Theory, and the Issue of Correlation," Theory \& Psychology 23, no. 5 (2013): 576-590.

${ }^{25}$ Gabriel Abend, "What Are Neural Correlates Neural Correlates of?," BioSocieties 12, no. 3 (2017): 416.
} 


\section{Examples of research areas - Why do we need first person data?}

\section{Human consciousness}

Contemporary neuroscience is attempting to understand consciousness through the latest technologies and advanced research methods. Although today's neural models, related to various aspects of consciousness, are available and experiments point to the neuronal correlates of consciousness, we are still in a situation involving an explanation of how the neurobiological and phenomenological aspects of consciousness relate to each other. ${ }^{26}$ As has already been mentioned, the neurophenomenological research program is, apart from others, associated with the personality and work of Francisco Varela, biologist, phenomenologist and philosopher with a knowledge of Eastern and Buddhist philosophy, the contemplative tradition of which become the inspiration for his neurophenomenological study of consciousness. ${ }^{27}$ Varela claims that neurophenomenology seeks articulations by mutual constraints between the field of phenomena revealed by experience and the correlative field of phenomena established by the cognitive sciences. ${ }^{28}$

The main idea of Varela's neurophenomenology that we have to focus on relates to the structure of human experience that create the link between mind and consciousness and was considered a potential solution of the hard problem of consciousness. ${ }^{29}$ Varela claims that experience is indeed a personal event, but not "private", because the subject is not isolated. (In this context it is possible to note that the problem of the subject's isolation was criticized already by Husserl's critics and this issue was discussed not only within phenomenology but also within other philosophical streams). Consciousness of a person is always linked to a consciousness of others. Varela therefore claims that the usual opposition of first-person versus third-person accounts is misleading. "It makes us forget that so-called third-person, objective accounts are done by a community of concrete people who are embodied in their social and natural world as much as first-person accounts." ${ }^{30}$ Varela's method, as he describes it, is his own synthesis of phenomenology in the light of modern cognitive science and other traditions that focus on human experience. ${ }^{31}$ In contrast to representationalism, Varela turns to alternative orientation, which claims that the mind and the world are "mutually overlapping". 32

As Roy points out, neurophenomenology was developed as a kind of methodological remedy to the hard problem. This Varela's suggestion, in contrast to Chalmers' expectation, does not necessarily require the naturalist principle of explanation. The elimination of the explanatory gap should be done by enriching "emergentist framework with the

\footnotetext{
26 Thompson, Lutz, Cosmelli, "Neurophenomenology," 40.

${ }^{27}$ Robert Garfield McInerney, "Neurophenomenological Praxis: Its Applications to Learning and Pedagogy," in Neurophenomenology and Its Applications to Psychology, ed. Susan Gordon (Springer Science+Business Media New York 2013), 45-47.

${ }^{28}$ See Chalmers, "Facing up to the Problem of Consciousness".

${ }^{29}$ See Varela, "Neurophenomenology".

${ }^{30}$ Varela, "Neurophenomenology," 340.

${ }^{31}$ Varela, "Neurophenomenology," 336.

${ }^{32}$ Varela, "Neurophenomenology," 346.
} 
introduction of a level of first-person description of the explanandum as well as of some reciprocal constraints between this level and the other ones". ${ }^{33}$ The descriptive gap will consequently be closed and the explanatory gap disappear. Roy points out, however, that this neurophenomenology without emergentism cannot be a solution to the hard problem, it is not a naturalist doctrine, and "mutual constraints per se do not and cannot deliver the sought-for naturalist explanation of consciousness" ${ }^{34}$ Gallagher reminds us, however, that Varela's ambition is not to provide a solution, but a kind of remedy. Providing a solution to the problem would have to assume the acceptance of the problem with its defined assumptions - in this case acceptance of the assumptions of classic naturalism. Varela was, however, reluctant to follow this path. "The remedy", as Gallagher explains, "was indeed the circumvent of the problem by reconceiving nature". ${ }^{35}$

Regardless of the complexity of the hard problem of consciousness, and in general the nature of this problem or even its existence (and other problems such as what naturalization means) within the broad discussion of philosophy of mind, neurophenomenology, whether in a more or less radical form, attempts to contribute to research on phenomenal consciousness, but also in other areas where experience is significant (see the following subsections). Less ambitious and narrowly defined versions of neurophenomenology find practical applications, although limited, in laboratories of cognitive sciences that cooperate with specialists in first-person methodology that participate in short interventions. ${ }^{36}$ As Bitbol and Petitmengin have mentioned, this kind of participation enables "avoiding the major conceptual shift that would ensue from challenging the ontological priority given to the third-person approach". ${ }^{37}$

Typical experiments related to consciousness research are based on tasks that are performed by subjects watching indifferent patterns that change over time on the computer screen. Subjects should press the button when the shape becomes a 3D object. Throughout the experiment, brain activity (third person data) is monitored in subjects through EEG. In addition, subjects are required to report briefly on their experience (first person data). In order to be able to report on their experience to a sufficient extent, subjects must be trained in advance. These reports should reveal subtle changes in the subject's experience. As Lutz claims, this type of qualitative first-person data is usually omitted from brain-imaging studies, but if we use methodological precautions, we can link this data with quantitative measures of neural activity. ${ }^{38}$ At the end of the experiment, the researchers found that when the first person data was combined with an analysis of neural processes, the opacity

${ }^{33}$ Jean-Michel Roy, "Time as the "Acid Test" of Neurophenomenology," Constructivist Foundations 13, no. 1 (2017): 103.

${ }^{34}$ Ibid.

35 Shaun Gallagher, “Internatual Relations," Constructivist Foundations 13, no. 1 (2017): 111.

${ }^{36}$ Michel Bitbol and Claire Petitmengin, "Neurophenomenology and the Micro-phenomenological Interview," in The Blackwell Companion to Consciousness. Second Edition, ed. Susan Schenider, Max Velmans (Hoboken: John Wiley \& Sons Ltd Bitbol and Petitmengin, 2017), 727.

${ }^{37}$ Ibid.

${ }^{38}$ Antoine Lutz and Evan Thompson, "Neurophenomenology. Integrating Subjective Experience and Brain Dynamics in the Neuroscience of Consciousness,", Journal of Consciousness Studies 10, no. 9-10 (2003): 44. 
of the brain responses was reduced. In addition, the original dynamic categories of neural activity were detected. ${ }^{39}$

\section{Religious and contemplative experience}

Husserl's transcendental phenomenology "brackets" the natural attitude of scientific objectivism, in order to identify the invariant structure of pre-subjective experience. Heidegger develops this into an existential phenomenology, which sees the person as a being in the world - always situated historically, culturally and linguistically. Merleau-Ponty stresses the "subject body" as constitutive of our perception of the world, arguing that a scientific "view from nowhere" is impossible. Phenomenologists influence subsequent sociological and psychological studies of intersubjectivity, consciousness and meditation.

Humanistic and transpersonal psychologists subsequently adopt meditative methods as techniques of "self-actualization" inducing transcendental experiences..$^{40}$ Varela uses Asian traditions, explicitly Buddhism (as living manifestations of an active, disciplined phenomenology, as he says), as an instrument to cultivate our scientific and western tradition. ${ }^{41}$ The question as to why Buddhism becomes a source of inspiration for research has an obvious answer. For Buddhists, contemplation and "mental training" is an essential part of their lives and practice. Subjects that are able to deliberately create, maintain and report on certain types of mental states, with a high degree of phenomenological accuracy, could provide a way of testing and a way of studying the causal effectiveness of mental processes. ${ }^{42}$ Contemplative training therefore cultivates a capacity for sustained attentive awareness of the moment-to-moment flux of experience. ${ }^{43}$

Tibetan Buddhism differentiates between these two groups of practices: "concentration" and "awareness" or "mindfulness" types. These essential structures of experience in meditation include the subject-object differentiation, restriction of attention to pure subjectivity, focus of attention specifically on one object at the exclusion of other objects, or the presence of a space-like field of awareness in which its referents (objects of experience) appear, etc. ${ }^{44}$ Varela puts together the "first-person" perspective of a well-trained experimental subject with the "third-person" perspective of an outside observer (a scientist measuring brain activity).

\footnotetext{
${ }^{39}$ Ibid.

${ }^{40}$ Steven, Stanley, "Meditation, Overview," in Encyclopedia of Critical Psychology, ed. Thomas Teo (Springer Science+Business Media New York 2014), 1166.

${ }^{41}$ See Varela, "Neurophenomenology".

${ }^{42}$ Evan Thompson, "Neurophenomenology and Contemplative Experience," in The Oxford Handbook of Religion and Science, ed. Philip Clayton (Oxford University Press, 2009), 231.

${ }^{43}$ Francisco Varela, Evan Thompson and Eleanor Rosch, The Embodied Mind: Cognitive Science and Human Experience (MIT Press, 1991), 230.

${ }^{44}$ Olga Louchakova-Schwartz, "Cognitive Phenomenology in the Study of Tibetan Meditation: Phenomenological Descriptions Versus Meditation Styles," in Neurophenomenology and Its Applications to Psychology, ed. Susan Gordon (Springer Science+Business Media New York 2013), 66-67.
} 
In experiments with meditation, ${ }^{45}$ namely Deity Yoga, after 20 minutes of meditation, all participants manifested a dramatic increase in performance in visual and spatial work memory tasks compared to other groups. In terms of visual cognition, these results suggest that the Yoga Deity trains the ability to access increased visual-spatial resources, possibly by engaging a powerful observer network that controls the allocation of brain resources in the working memory unit. It has been shown, for example, that there is a significant difference in the perception of time and space, in the perception of oneself, including the body, etc. This experiment demonstrated that visual processing can be trained and that mental imagery utilizes the networks of the brain associated with normal visual processing, as would be in the case of computer games. "However, if meditation includes more than the visual modalities of internal imagery, e.g., semantic processing or body schema, the involvement of executive attention will include subsystems responsible for these different modalities and be more nuanced than in the case of pure mental visual imagery." 46

It should be noted, however, that the acceptance of Buddhist meditations into scientific practice raises debate, as many of the initial research relates to doubts about methodology and hence the results. One of the problems is whether the trained subject is really able to achieve mental states that are characteristic for Buddhist monks. As Kotherová shows, Buddhism has been gradually reduced to meditation techniques that we are not able to repeat and replicate in the West. ${ }^{47}$ The concept of meditation is also problematic, as it is faced with problems of operationalization of the phenomena examined, incorrectly asking research questions and formulating hypotheses. ${ }^{48}$ The question, however, is whether this is necessary for research if we do not pursue purely religious experience, but our task will be to apply the method outside the field of religious research (see other subsections of this section). Another complication is determining when an experimental subject can be considered well-trained (for broader discussion see part four).

\section{Research on emotions}

In their first-person neuroscience research, Northoff and Heinzel use a combination of first-person and third-person data for empirical research on emotions. In their research they use a "categorical approach" based on third-person methodology, which is based on an evaluation of emotions (positive, neutral, negative categories) using the International Affective Picture System. This procedure provides the neuronal correlates of the emotional categories obtained with fMRI. Since emotions are subjective, these categories are based on a first-person perspective and the standard valency scale is determined by the experience of research subjects. Neuroscientific investigations in this regard practically combine

\footnotetext{
${ }^{45}$ For an example of the experiment, see Louchakova-Schwartz, "Cognitive Phenomenology in the Study of Tibetan Meditation".

${ }^{46}$ Louchakova-Schwartz, "Cognitive Phenomenology in the Study of Tibetan Meditation," 77.

47 Silvie Kotherová, „Problematika experimentálního výzkumu buddhistických meditací, Sociální studia 4 (2015): 75.

${ }^{48}$ Dilwar, Hussain, Braj Bhushan, "Psychology of meditation and health: present status and future directions", International Journal of Psychology and Psychological Therapy 10, no. 3 (2010): 445-447.
} 
data from different perspectives. In their approach, Northoff and Heinzel try to use the potential of first-person data. According to their approach, emotions do not only have to be classified by categories commonly held in a third-person perspective, but emotions can also be classified by the continuous first-person experience of the investigated subject. ${ }^{49}$

The experiment in which neuronal correlates can be distinguished regarding a first-person perspective (continuous emotional experience in first person) and third-person perspective (categorical distinction of emotions) is described as follows: The continuous first-person experience can for example be obtained on a visual analogue scale with a continuum between 1 and 9 of emotional valences - this continuous or parametric analysis can be called firstperson approach. In this case, the first-person experience of the emotions can directly be related to the neuronal correlates as measured in $\mathrm{PMRI}$. Such a direct relation is possible since the emotional experience has been transformed via a visual analogue scale into numerical values that can be correlated with the values resulting from the fMRI measurement. It has to be considered that the numerical values are not identical with the emotional experience itself. In a next step one might then compare the fMRI results from both approaches, the categorical or third-person versus the parametric or first-person analysis. ${ }^{50}$

The study showed that there are differences between first-person and third-person neuronal correlates. The results demonstrate that there are areas in the brain, cortical midline structures that are associated with the first-person experience of emotions. It seems that these regions can "preferentially process self-referential stimuli as distinguished from non-self-referential ones". ${ }^{51}$ This example represents the reason why Northoff and Heinzel believe that the first-person perspective is important - it provides information that cannot be obtained by a third-person approach. Moreover, the first-person perspective may be important to provide new insights into the neuronal correlates of mental states. ${ }^{52}$

The neurophenomenological framework is also currently used in combination with new approaches that seek to extend and modify neurophenomenology. An example is cardiophenomenology and its combination with a micro-phenomenological interview. This is the field of emotions that is the domain for this type of research. Depraz and colleagues in their research on surprise in depression demonstrate that an analysis of first-person data leads to the emergence of new unseen categories. In their research, third-person data are useful in creating a temporal framework for unfolding the experience and lived experience of the third-person data. Empirical-experiential first-person data specified by body category and new sub-categories such as perception and kinesthesis emerged. ${ }^{53}$ As with every kind of innovative research, these kinds of emotions research also have their limitations.

\footnotetext{
${ }^{49}$ See Northoff and Heinzel, "First-Person Neuroscience," 3.

${ }^{50}$ Northoff and Heinzel, "First-Person Neuroscience," 4-5.

${ }^{51}$ Northoff and Heinzel, "First-Person Neuroscience," 6.

52 Ibid.

${ }^{53}$ Natalie Depraz, Maria Gyemant and Thomas Desmidt, "A First-Person Analysis Using Third-Person Data as a Generative Method: A Case Study of Surprise in Depression," Constructivist Foundations 12, no. 2 (2016): 190, 194.
} 


\section{Education}

Another area where one can talk about the usefulness of neurophenomenology is education. Education may be defined as an intentionally oriented process towards change in individuals and in society. ${ }^{54}$ This is why it is possible to seek a connection between education and neurophenomenology. It is a fairly common topic of expert research. Intentionality is a key notion of Husserl's phenomenology and as Strollo claims, "the link between education and intentionality, or rather between the educational action and the motivation driving it, might be analysed from different points of view: starting from the assumption that every educational action is intentional, intentionality can be considered without any observational counterpart, and it opens up, in pedagogy, to eminently philosophical and theoretical approaches". ${ }^{55}$

The key to the education system is not individual existence, but the intersubjectivity that Edmund Husserl also tried to take into account in his late work. It should be said that Husserl was not particularly successful, nor even his successor Martin Heidegger. Intersubjectivity in phenomenology was considered by other philosophers, such as Eugen Fink, ${ }^{56}$ Jan Patockka, ${ }^{57}$ or Jean-Paul Sartre. ${ }^{58}$ There is the assumption that intersubjectivity is necessary to overcome the strongest objections to the application of neurophenomenology in practice (reports in third person). Indeed, this intersubjective approach makes it possible to combine neurophenomenology and education.

"One of the distinctive elements of the higher primates would, in fact, be to excel in providing an interpretation of the other's mind. This skill is a particular kind of intelligence, connected to the understanding of mental states, desires, intentions, and beliefs, based on the other's bodily presence." 59 Learning thus seems to be something like imitation. In neurophenomenology, the educational process is therefore seen as a "transformation" process.

On the basis of intersubjectivity - coexistence - one can state that it is possible to use not only one's own experience in education. As Strollo points out, there is one way to build models, which are not just based on the individual experience.

It assumes a new ability, the specularity: one was thinking, modelling and reasoning, in a given situation, as the others would think, model, reason in the same situation. This is one of the main aspects of the notion of specularity, which is useful to analyse the cohesion of human societies. When addressing a new situation, the human being builds up models as a function of what one observes but also, and above all, as a function of what one thinks that the other people would modelize if they were in one's shoes. ${ }^{60}$

\footnotetext{
${ }^{54}$ For example, Maria Rosaria Strollo, Neurophenomenology of Education (FrancoAngeli s.r.l., Milano, Italy, 2018).

55 Strollo, Neurophenomenology of Education, 20.

${ }^{56}$ See Eugen Fink, Grundphänomene des menschlichen Daseins (Freiburg 1979).

${ }^{57}$ See Jan Patočka, Heretical Essays in the Philosophy of History, translated by Erazim Kohák, edited by James Dodd (Chicago, IL: Open Court, 1996).

${ }^{58}$ See Jean-Paul Sartre, Being and Nothingness, trans. Hazel E. Barnes (Routledge 2003).

59 Strollo, Neurophenomenology of Education, 104.

${ }^{60}$ Strollo, Neurophenomenology of Education, 38.
} 
Scholars point out that first-person data collection can be very useful in education. Their value lies in a deeper understanding of the ways of learning and thus in the improvement of pedagogical practices. There are a number of experiments and practices that use a phenomenological and neurological perspective, and many educators (researchers) commonly use it in their practice.

McInerney describes one of these experiments and calls it the game of identity, with many volunteer students coming in front of a classroom and sitting on chairs. He then asks each student to alternate and identify himself or herself using any kind of etiquette or experience, including things such as gender, ethnicity, race, profession, likes or dislikes and habits. One of the simpler goals of identity play is to get students to move their bodies (this facilitates thinking and learning in terms of embodiment). When volunteers identify with each other, other students respond to whether they believe that identification is relational (the meaning of identity is born from a certain interpersonal relationship), positional (the meaning of identity) is born from some social position usually associated with power and hierarchies) or context (that is, the meaning of identity seems to be more about context). ${ }^{61}$

For Varela and his colleagues, so-called "context-dependent know-how" is the "essence of creative knowledge". ${ }^{62}$ It is this know-how that occurs when we follow the pupil as it is placed. The pupil's abilities are, as Varela and his colleagues say, "rooted in the structures of our biological incarnation, but they live in the domain of consensual action and cultural history". ${ }^{33}$ McInerney asks students to physically move either closer or further away depending on our interpretation of the identity; in other words, do the students identify with each other, and if so, how is this identification represented in terms of their physical proximity, sense of closeness and community? The point here is to feel the enacting of interpersonal connectivity and community. Theoretically, there is an inseparability of intention and attention: thus to observe and interpret one's intentions is to interpret meaning and experience in relation to one's perceptual and apperceptual attention. ${ }^{64}$

\section{Insurmountable problems or a thorny road to success?}

As was explained above, neurophenomenology represents a discipline that is based on a very challenging methodology which opens many questions related to its justifiability and possibilities for its improvements that will meet the rigorous requirements of scientific third-person research. In this section, we review recent attempts to unify first and third person methodology to provide valuable data. This review is based especially on those studies that offer a critical reflection on methodological issues and discuss the possibilities of developing neurophenomenology. As Thompson, Lutz and Cosmelli point out, there is a need to come up with an explanatory framework that will be able to overcome the

\footnotetext{
${ }^{61}$ See McInerney, "Neurophenomenological Praxis".

${ }^{62}$ Varela, Thompson, Rosch, The Embodied Mind, 148.

${ }^{63}$ Varela, Thompson, Rosch, The Embodied Mind, 149.

${ }^{64}$ McInerney, "Neurophenomenological Praxis," 45-47.
} 
methodological, conceptual and epistemological explanatory gap in relation to the phenomenal and physiological features of consciousness. ${ }^{65}$

\section{Conceptual and epistemological issues}

As Northoff and Heinzel show, the first-person perspective and third-person perspective do not represent an appropriate conceptual framework for first-person neuroscience. The firstperson perspective is related to experimental access to mental states. The research deals with the question - "What is it for a person's experience and mental state?" Questions related to mental states are investigated within first person mentoscience, as Northoff and Heinzel call it. The authors recall that this approach can be called "objective phenomenology" in Nagel's ${ }^{66}$ term. The third-person perspective is related to empirical access to neuronal states. The research deals with the question "What is the neuronal state?" Disciplines related to this investigation may be labelled by the term third-person neuroscience. Northoff and Heinzel argue that first-person neuroscience, which is a link between the third-person and first-person perspective, presupposes its own perspective which they call the first-brain perspective. The first-person neuroscience within this perspective allows indirect access to the brain itself. First-brain perspective is related to empirical access to neuronal states in relation to mental states. The research question is - "What is it like for the brain to generate those neuronal states that are experienced as mental states?" 67

Northoff and Heinzel consider a first-brain perspective a perspective that can overcome the conceptual problem of epistemic dualism between first-person and third-person perspectives. As the authors realize, however, there are conceptual philosophical issues that emerge. The first-brain perspective can be rejected for two main reasons. The first reason is that the first-brain perspective can be identified as conceptually contradictory. The second reason arises from the arguments of epistemic monism (approaches such as eliminative materialism $)^{68}$ and the first-brain perspective will be labelled as empirically superfluous. Thus, the proposed first-brain perspective represents an intermediary stance, but a specific form of this stance is not obvious, which raises doubts about this approach. The authors ask the question as to whether the first-person and third-person perspectives are within the first-brain perspective purely linked to each other, or whether it is a "genuinely unifying ground", which means that the first-brain perspective "would need to be characterized by states different from both neuronal and mental states since otherwise it would not be genuinely unifying". ${ }^{69}$ Thompson, Lutz and Cosmelli in this respect summarize the efforts of neurophenomenology which are not based on aims "to close the explanatory gap (in the

65 Thompson, Lutz, Cosmelli, "Neurophenomenology," 40.

${ }^{66}$ Thomas Nagel, The View from Nowhere, (Oxford: Oxford University Press, 1986).

${ }^{67}$ See Northoff and Heinzel, "First-Person Neuroscience".

${ }^{68}$ Paul M. Churchland, "Eliminativism and the Propositional Attitudes," The Journal of Philosophy 78 (1981): 67-90.

${ }^{69}$ See Northoff and Heinzel, First-Person Neuroscience. 
sense of conceptual or ontological reduction), but rather to bridge the gap by establishing dynamic reciprocal constraints between subjective experience and neurobiology". ${ }^{70}$

Moreover, neurophenomenology cannot be considered a solution to this problem, but rather a research program that seeks to address this task. ${ }^{71}$ The bridging explanatory gap remains a major problem. In this regard, Ciechanowski recalls the argument against reductionism, which states that the correlational or even causal relations between the entities are not sufficient to postulate an ontological identity. This argument can also be used, according to Ciechanowski, for the case of first-person and third-person data because the only relations we observe are correlational or causal in the best cases. Without bridging the gap, it is only possible to speculate about connections between the two levels of data. ${ }^{72}$

\section{Methodological issues}

\section{The approach of a methodologically trained subject}

The methodology is a key issue in the neurophenomenological research program. Varela's field of neurophenomenology assumes that sustained training in a method will lead to uncovering new aspects of experience that were not available before. Within this process, phenomenological reduction is crucial because it overcomes the habit of automatic introspection. Within this neurophenomenological framework, "science and experience constrain and modify each other as in a dance", which creates the potential for transformation. ${ }^{73}$ This approach is complicated, however, because it is in contrast the style of traditional scientific work and it is hard to change the habits of science. Varela claims that we cannot expect completely new insights into empirical mechanisms from the neurophenomenological approach. ${ }^{74}$

This suggested first-person method is based on "epoché", which is the term for Husserl's phenomenology. Its essence is to try to get rid of, or rather to temporarily "bracket", all the prejudices we have about things and experiences (suspending judgment). Thanks to this, attention can be focused on the pure object (noema) and on the process of experiencing (noesis). "During the epoché, an attitude of receptivity or 'letting go' is also encouraged, in order to broaden the field of experience to new horizons, towards which attention can be turned. Distinctions usually do not arise immediately, but require multiple variations. The repetition of the same task, for instance, enables new contrasts to arise, and validates emerging categories or invariants. Training is therefore a necessary component to cultivate all three phases, and to enable the emergence and stabilization of phenomenal invariants." 75

\footnotetext{
70 Thompson, Lutz, Cosmelli, "Neurophenomenology," 89.

${ }^{71}$ Ibid.

72 Ciechanowski, "Philosopher's Stone," 204.

${ }^{73}$ Varela, "Neurophenomenology," 346.

${ }^{74}$ Varela, "Neurophenomenology," 345.

${ }^{75}$ Lutz, Thompson, "Neurophenomenology," 37-38.
} 
Lutz defines neurophenomenology as "gathering first-person data from phenomenologically trained subjects as a heuristic strategy for describing and quantifying the physiological processes relevant to consciousness." ${ }^{76}$ First-person data are important to uncover new third-person data and these data include cognitive neuroscientific research.

The aim of the phenomenological analysis is to achieve "the invariant" of the object in our experiences. We achieve this invariant after "bracketing" or the suspension of our judgments about the object, its relationship to the world and our experience. This procedure consists of three parts - suspension, redirection, and receptive openness. To master this seemingly simple process is not particularly easy, because "letting-go" all our previous experiences, prejudices and beliefs about the matter truly requires deep concentration. Only a carefully trained individual can do this. Participant training is also one of the key stages of neurophenomenological research. According to Varela, sustained training in a method can make available aspects of experience that were not available before.

The problem with this method, Varela says, is that "it is hard work to train and stabilize new methods to explore experience" and "it is hard to change the habits of science in order for it to accept that new tools are needed for the transformation of what it means to conduct research on the mind and for the training of succeeding generations" ${ }^{77}$ It is very difficult to explain exactly what such training of epoché and phenomenological reduction is. It can basically be compared to some form of meditation or concentration, where the subject does not focus on his opinions, theories and experiences, but tries to "put aside" these "to bracket" them, and instead focuses on the way we experience these things.

\section{A phenomenologically enlightened experiment and methodologically trained interviewers}

In addition to neurophenomenology ${ }^{78}$ and indirect phenomenology, ${ }^{79}$ Shaun Gallagher proposes a third approach: Frontloaded phenomenology or phenomenologically enlightened experimental science. ${ }^{80}$ It begins with the experimental design and "the idea is to front-load phenomenological insights into the design of experiments, that is, to allow the insights developed in phenomenological analyses to inform the way experiments are set up. To front-load phenomenology, however, does not mean to simply presuppose phenomenological results obtained by others. Rather it involves testing those results and more generally a back-and-forth movement between previous insights gained in phenomenology and preliminary trials that will specify or extend these insights for purposes of the particular experiment or empirical investigation." ${ }^{81}$

\footnotetext{
${ }^{76}$ Lutz, Thompson, "Neurophenomenology," 32.

77 Varela, "Neurophenomenology," 347.

78 See Varela, "Neurophenomenology".

${ }^{79}$ Glenn Braddock, "Beyond Reflection in Naturalized Phenomenology," Journal of Consciousness Studies 8, no. 11 (2001).

${ }^{80}$ See Shaun Gallagher, "Phenomenology and Experimental Design Toward a Phenomenologically Enlightened Experimental Science," Journal of Consciousness Studies 10, no. 9-10 (January 2003).

${ }^{81}$ Gallagher, "Phenomenology and Experimental Design," 92.
} 
It is therefore quite the opposite of the previous approaches, which begin with either the experiment itself or the training as Varela suggested. Phenomenology in this case represents the framework within which the experiment takes place. The subject in this experiment does not need to know anything about his own experiences, because they do not give a report of their experience in all kinds of research.

This approach offers insights for future development of neurophenomenology. Bockelman, Reinerman-Jones and Gallagher deal with methodological problems and possibilities for improving neurophenomenological methodology. Their experiment focused on the experience associated with space flights. During the experiment, space-travel environments were simulated and aesthetic, spiritual, or religious experiences were explored which are related to several affective states. The participants were measured for neurological and physiological data and subsequently subjected to phenomenological and psychological interviews. The aim was to investigate the correlation between the phenomenological experience of the first person with the measured physiological data. The authors summarize the experiment as successful and point out the possibilities of using neurophenomenology. They make three recommendations for improving the neurophenomenological methodology. ${ }^{82}$

The first important methodological point concerns the development of a shared mental model, which must be followed during the research. There is a need to ensure an understanding of every part of the research in the context of the entire research goal, which is particularly important for interdisciplinary research projects such as neurophenomenology. In this respect, the shared lexicon and conceptual framework is important. This approach requires considerable time investment in the ongoing training of researchers on methods and theories of neurophenomenology. The second important condition for the development of a neurophenomenological method is the high standard of experimental design and need to achieve variable control, reliability and generalization. In this respect, it is suggested that neurophenomenological research is based on the experience of cognitive science and psychology which have a longer tradition. The third point that Bockelman with his colleagues mention, is the importance of focusing on the interviewer rather than on the participant. There is a need to ensure that the interviewer will be able to support the participant to accurately reflect his or her lived experience, which requires interviewer training. In this aspect, neurophenomenology differs from traditional cognitive science and offers opportunities for developing exploration of lived experience. ${ }^{83}$

\section{Emerging methodological problems}

Phenomenological and neurophenomenological methods are faced with several methodological questions related to experimenter and respondent biases or the fact that second-person data is mistakenly considered first-person data ${ }^{84}$ Ciechanowski in this respect reminds us of the fact that cognitive and affective illusions and biases are almost impossible to elimi-

\footnotetext{
${ }^{82}$ Bockelman et al., "Methodological Lessons," 5.

${ }^{83}$ Bockelman et al., "Methodological Lessons," 5-7.

${ }^{84}$ Ciechanowski, "Philosopher’s Stone," 203.
} 
nate in experimental research. Phenomena such as illusion of control, choice blindness, introspection illusion, social desirability bias, or biases of experimenters and participants influence behaviours within research. Another significant issue that Ciechanowski points out and which refers to Churchland ${ }^{85}$ and Dennett's ${ }^{86}$ arguments is that it can be stated that first-person data in experiments is not directly studied at all - instead of that, secondperson data is studied in the best cases. There is a separation of emotions, however, a perception from the situation when the interview takes place. This situation is already affected by many biases. In addition, another significant factor affecting the interview is the participant's memory when there is a time lag between the experience and the interview. ${ }^{87}$

The study of consciousness, or mind-wandering, illustrates the problem of neurophenomenological methodology. As Head and Helton warned in their study, researchers should be very careful when using the thought probes to retrospectively predict a past performance. The correlations obtained are not sufficient for establishing causation. In this regard, Head and Healton point out that "given the temporal order where performance precedes the probe report, performance is more likely to casually influence the probe report than the probe report is to casually influence performance" ${ }^{88}$ Self-reports may be influenced by performance and cause can be mistaken for an effect.

First-person research, based on phenomenological tradition, attempts to avoid the method of naive introspection, which does not lead to the obtaining of first-person data, but to a collection of opinions, beliefs or explanations. Neurophenomenological research based on Varela's research program uses phenomenological reduction to avoid uncritical introspection. In this respect, Strle mentions important questions that emerge. We cannot be sure whether a participant is practicing a phenomenological approach, or whether it is based on his or her normal habitual practice that leads to the report of his or her beliefs. The solution proposed by Varela ${ }^{89}$ described above, is in disciplined training. Strle believes, however, that Varela's approach represents the greatest challenge, or maybe an obstacle for the whole research program. If this training is to be implemented, there is a need to know how it should be done, how long it should take, and above all, the criteria on which it should be assessed depending on whether the training has been done properly. Finally, there must be a person to judge all of this..$^{90}$

\footnotetext{
${ }^{85}$ See Patricia Smith Churchland, "Can Neurobiology Teach us Anything about Consciousness?," Proceedings and Addresses of the American Philosophical Association 67, no. 4 (1994): 23-40.

${ }^{86}$ See Daniel Dennett, Consciousness Explained.

${ }^{87}$ Ciechanowski, "Philosopher's Stone," 204.

${ }^{88}$ James Head and William S. Helton, "The Troubling Science of Neurophenomenology," Experimental Brain Research 236, no. 9 (2018): 2466, 2467.

${ }^{89}$ See Varela, "Neurophenomenology," 330-349.

90 Toma Strle, "On Mutual Enrichment between First- and Third-Person Sciences and Phenomenological Methodology," Constructivist Foundations 12, no. 2 (2017): 209-210.
} 


\section{Discussion}

Although it seems that the results of first-person science do not bring anything fundamentally new, it can be stated with certainty that qualitative data obtained in this way can be incorporated into strictly scientific experiments. Scientists themselves are well aware that only a quantitative analysis of the contents of consciousness is very inadequate and that if they want to embrace it once in their full breadth and depth, better measuring instruments are not enough. First-person data are unforgettable in this sense, as it is impossible to examine consciousness without the active involvement of the subject itself.

It seems that the path taken by Varela, Luzt, Gallagher, and other researchers represents a promising way in the right direction. Training methods, based on the principle of deep concentration or meditation, are the logical way for a subject to report on the pure phenomena of his or her consciousness. Consciousness is such a complex collection of various phenomena, processes, and events that only the task - "bracketing" the unimportant and fully concentrating on those we want to acquire and inform about - will take a huge amount of time for scientists. It will always be subjective reports, however, and never really "objective". The question is whether in research of human consciousness, one can expect something like "objective" reports and whether this is even desirable. Phenomenology philosophers and followers of the original ideas of the brilliant method of the phenomenological reduction of Edmund Husserl have always emphasized that we have the perspective that our position in the world gives us, in which we are thrown. There is no "sight of the eye of God" and it actually is not needed. This does not mean that we should give up research on consciousness.

It is not certain if there is a chance that human consciousness will be controlled, measured, and contained by the devices that humans will create in the future. It instead seems that there will be always a very narrow section, which will be to some extent distorted and unclear. Moreover, uncertainty is something we undoubtedly need for our freedom. First-person data will be always an important part of this research and we should not give up searching for ways to use it. We should try, on the contrary, to improve the training methods and the reporting methods of the subject. By combining quantitative and qualitative data, science can make a great contribution in many areas of human activity, including education, but also in psychology and medicine. If these experiments are successful, then there is no point in asking whether there can be pure first-person science.

One can say with certainty that there is still a gap between first-person and third-person perspectives. It is possible that bridging this gap is unattainable. Moreover, the statements of the participants do not directly represent their lived experience, but they are influenced by many factors, they depend on the presentation skills of the participant, on their memory, etc. The problem is that we do not have another approach to lived experience. It is possible, however, to acknowledge all the shortcomings of this phenomenological research and analyze the factors influencing the statements about the experience. 
Social neuroscience cannot exist without the social sciences - and therefore it cannot avoid the problems of social sciences such as conceptualization of terms and mental phenomena whose neuronal correlates or other characteristics are sought. First-person neuroscience offers the possibility, although very limited due to numerous problems, of characterizing the experience of an experimental subject - and thus of understanding a mental phenomenon experienced at a different level than in the case of objectivised categories based on psychological questionnaires or conceptual definitions grounded in theoretical concepts and cultural-social preferences. This option remains, however, at the level of hope and vision for the future direction of this ambitious research agenda. The results of the current studies must be taken with caution, but it can be also seen as an inspiration. For the development of neurophenomenology and first-person neuroscience, there will be a need to accurately capture the course of all experimental methods and research contexts in order to work on an improvement of methods and enable their replication.

\section{Conclusion}

In this paper, we presented efforts to include first-person data in empirical third-person research through a neorophenomenological framework. This research program provides inspiration for new research methods and takes into account data on subjective experience that has been ignored in science for logical reasons. The current approaches of first-person neuroscience and neurophenomenology attempt to create a conceptual framework for bridging the gap between first-person and third-person perspectives and make an effort to modify and extend methodological procedures that overcome the difficulties of naive introspection. It turns out that first-person data remains a very complicated issue and various problems persist, although a great deal of research indicates that in the case of well conducted research first-person data helps reveal new information and categories useful for interpretation of third-person data.

\section{Bibliography}

Abend, Gabriel. "What are Neural Correlates Neural Correlates of?" BioSocieties 12, no. 3 (2017): 415-438. Bickle, John, Mandik, Peter and Landreth, Anthony. "The Philosophy of Neuroscience." In The Stanford Encyclopedia of Philosophy, edited by Edward N. Zalta (Summer 2012 Edition), https://plato.stanford.edu/ archives/sum2012/entries/neuroscience.

Bitbol, Michel, Petitmengin, Claire. "Neurophenomenology and the Micro-phenomenological Interview." In The Blackwell Companion to Consciousness. Second edition. Edited by Susan Schenider and Max Velmans, 726-739. Hoboken: John Wiley \& Sons Ltd, 2017.

Bockelman, Patricia, Reinerman-Jones Lauren, Gallagher, Shaun. "Methodological Lessons in Neurophenomenology: Review of a Baseline Study and Recommendations for Research Approaches." Frontiers in Human Neuroscience 7, (October 2013): 1-9. 
Braddock, Glenn. "Beyond Reflection in Naturalized Phenomenology." Journal of Consciousness Studies 8, no. 11 (2001).

Chalmers, David John. "Facing up to the Problem of Consciousness." Journal of Consciousness Studies 2, no. 3 (1995): 200-219.

Churchland, Patricia Smith. "Can Neurobiology Teach us Anything about Consciousness?” Proceedings and Addresses of the American Philosophical Association 67, no. 4 (1994): 23-40.

Churchland, Paul M. "Eliminativism and the Propositional Attitudes." The Journal of Philosophy 78, no. 2 (1981): 67-90.

Ciechanowski, Leon. "Has the Philosopher's Stone of the Interaction Between First- and Third-Person Data Finally been Found?" Constructivist Foundations 12, no. 2 (2017): 203-205.

Dennett, Daniel. Consciousness Explained. Little, Brown and Co, Boston, 1991.

Depraz, Natalie, Gyemant, Maria, Desmidt, Thomas. "A First-Person Analysis Using Third-Person Data as a Generative Method: A Case Study of Surprise in Depression." Constructivist Foundations 12, no. 2 (2016): $190-203$.

Depraz, Natalie, Desmidt, Thomas. "Cardiophenomenology: A Refinement of Neurophenomenology." Springer. Phenomenology and the Cognitive Sciences 18, no. 3 (2019): 493-507.

Desbordes, Gaëlle, Negi, Lobsang T. "A New Era for Mind Studies: Training Investigators in Both Scientific and Contemplative Methods of Inquiry." Frontiers of Human Neuroscience 7 (November 2013).

Fink, Eugen. Grundphänomene des menschlichen Daseins. Freiburg, 1979.

Gallagher, Shaun. "Phenomenology and Experimental Design Toward a Phenomenologically Enlightened Experimental Science." Journal of Consciousness Studies 10, no. 9-10 (January 2003).

Gallagher, Shaun. “Internatual Relations.” Constructivist Foundations 13, no. 1 (2017): 110-113.

Head, James, William S. Helton. "The Troubling Science of Neurophenomenology." Experimental Brain Research 236, no. 9 (2018): 2463-2467.

Hussain, Dilwar, Braj Bhushan, "Psychology of meditation and health: present status and future directions", International Journal of Psychology and Psychological Therapy 10, no. 3 (2010): 439-451.

Husserl, Edmund. Ideas Pertaining to a Pure Phenomenology and to a Phenomenological Philosophy - First Book: General Introduction to a Pure Phenomenology. Translated by Kersten, F. The Hague: Nijhoff, 1982.

Husserl, Edmund: On the Phenomenology of the Consciousness of Internal Time (1893-1917). Translated by Brough, J.B. Dordrecht: Kluwer, 1990.

Kotherová, Silvie. „Problematika experimentálního výzkumu buddhistických meditací." Sociálni studia 4 (2015): 73-93.

Laughlin, Charles D., Rock, Adam J. "Neurophenomenology. Enhancing the Experimental and CrossCultural Study of Brain and Experience." In The Wiley-Blackwell Handbook of Transpersonal Psychology, edited by Harris L. Friedman and Glenn Hartelius, 268. John Wiley \& Sons, Ltd. Published, 2013.

Louchakova-Schwartz, Olga. "Cognitive Phenomenology in the Study of Tibetan Meditation: Phenomenological Descriptions Versus Meditation Styles." In Neurophenomenology and its Applications to Psychology, edited by Susan Gordon. Springer Science+Business Media New York, 2013.

Lo Dico, Giuseppe. “Neuroeconomics, Identity Theory, and the Issue of Correlation.” Theory \& Psychology 23, no. 5 (2013): 576-90. 
Lutz, Antoine, Thompson, Evan. "Neurophenomenology. Integrating Subjective Experience and Brain Dynamics in the Neuroscience of Consciousness." Journal of Consciousness Studies 10, no. 9-10 (2003): 31-52.

Merleau-Ponty, Maurice. Phenomenology of Perception. Routledge Classics, Taylor \& Francis, 2002.

McInerney, Robert Garfield. "Neurophenomenological Praxis: Its Applications to Learning and Pedagogy." In Neurophenomenology and its Applications to Psychology, edited by Susan Gordon, 45-47. Springer Science+Business Media New York, 2013.

Müller, Michal. "Challenges and Problems of Neuroeconomics: Several Tasks for Social Scientists.” Teorie védy / Theory of Science 40, no. 2 (2018): 157-190.

Nagel, Thomas. The View from Nowhere. Oxford: Oxford University Press, 1986.

Northoff, Georg, Heinzel, Alexander. "First-Person Neuroscience: A New Methodological Approach for Linking Mental and Neuronal States." Philosophy, Ethics, and Humanities in Medicine (2006). https://pehmed.biomedcentral.com/track/pdf/10.1186/1747-5341-1-3.

Patočka, Jan. Heretical Essays in the Philosophy of History, translated by Erazim Kohák, edited by James Dodd (Chicago, IL: Open Court, 1996).

Polák, Michal. Filosofie mysli. (Praha; Kroměříž: Triton, Západočeská univerzita v Plzni, 2013).

Redcay, Elizabeth, Schilbach, Leonhard. "Using Second-Person Neuroscience to Elucidate the Mechanisms of Social Interaction.” Nature Reviews Neuroscience 20 (2019): 495-505.

Roy, Jean-Michel. "Time as the "Acid Test” of Neurophenomenology." Constructivist Foundations 13, no. 1 (2017): 101-103.

Sartre, Jean-Paul. Being and Nothingness, translated by Hazel E. Barnes (Routledge, 2003).

Stanley, Steven. "Meditation, Overview." In Encyclopedia of Critical Psychology, ed. Thomas Teo (Springer Science+Business Media New York 2014), 1163-1168.

Strle, Toma. "On Mutual Enrichment between First- and Third-Person Sciences and Phenomenological Methodology." Constructivist Foundations 12, no. 2 (2017): 209-210.

Strollo, Maria Rosaria. Neurophenomenology of Education. (FrancoAngeli s.r.l., Milano, Italy, 2018).

Thompson, Evan, Lutz, Antoine Cosmelli, Diego. "Neurophenomenology: An Introduction for Neurophilosophers." In Cognition and the Brain: The Philosophy and Neuroscience Movement, edited by A. Brook and K. Akins (New York, NY: Cambridge University Press, 2005): 40-97.

Varela, Francisco, Thompson, Evan, Rosch, Eleanor. The Embodied Mind: Cognitive Science and Human Experience (MIT Press, 1991).

Varela Francisco J. "Neurophenomenology: A Methodological Remedy for the Hard Problem.” Journal of Consciousness Studies 3, no. 4 (1996): 330-349. 